DOI: 10.21315/aos2021.16.2.5

ARTICLE INFO

Submitted: $28 / 10 / 2020$

Accepted: 22/8/2021

Online: $22 / 12 / 2021$

\section{Use of Social Media in Dental Education: A Single Institutional Study}

\author{
Nor Faharina Abdul Hamid ${ }^{a *}$, Azlan Jaafar ${ }^{\mathrm{b}}$ \\ ${ }^{a}$ Centre of Restorative Studies, Faculty of Dentistry, Universiti Teknologi \\ MARA, 47000 Sungai Buloh, Selangor, Malaysia \\ ${ }^{b}$ Faculty of Dentistry, Universiti Sains Islam Malaysia, 55100 Kuala \\ Lumpur, Malaysia
}

${ }^{\star}$ Corresponding author: faharina@uitm.edu.my

To cite this article: Abdul Hamid NF, Jaafar A (2021). Use of social media in dental education: A single institutional study. Arch Orofac Sci, 16(2): 141-152. https://doi.org/10.21315/aos2021.16.2.5

To link to this article: https://doi.org/10.21315/aos2021.16.2.5

\begin{abstract}
Educational landscape has changed drastically over the past decades with the integration of technology to support the role of educators. The objectives of this study were to examine the use of social media application among dental students and to investigate significant demographic variables with regard to social media use for academic purposes. All dental students across all academic years were invited to participate in a self-administered questionnaire (content validated, pre-tested) survey conducted online via Google Forms. Overall response rate was $67.8 \%$. Of the 244 respondents, 99.1\% owned smartphones, with a majority of them were iPhone and Android users. Notably, 91.4\% of the respondents had access to internet data via a third generation (3G) mobile carrier and WiFi connection. A majority of the respondents (97.1\%) used social media to communicate or connect with friends whereas $5.7 \%$ of them used it for business purposes. There was no significant association between gender, year of study and type of internet access with the mean of social media usage for academic purposes $(p>0.05)$. Most of the respondents preferred YouTube $(74.6 \%)$ and Google $(73.7 \%)$ for seeking information in their study. In conclusion, we found that majority of respondents had acknowledged the importance of social media in education. Our findings suggest the potential value of integrating social media in teaching and learning activities to enhance students' learning experience.
\end{abstract}

Keywords: Dental education; dentistry; educational technology; Malaysia; social media

\section{INTRODUCTION}

Previously, many studies had reported the use of social media for educational purposes in various health science disciplines (Robinson et al., 2013; de Peralta et al., 2019; Nguyen et al., 2021; Sharka et al., 2021). Social media has served as a platform to improve and enhance online learning in delivering valuable information, participating in live presentation, or working as a platform in a group discussion for student (Gikas \& Grant, 2013; Rasiah, 2014).
With the improvement of digital technology and social media applications, the technology has become an essential communication tool for teaching and learning activities between the educators and students. The e-Learning Centre (i-LeC) of Universiti Teknologi MARA (UiTM) was established in December 2005 as one of the university's efforts to embark on e-learning activities. The centre acts as the core unit in initiating and implementing e-learning on a campuswide level that aims to comprehensively train and equip all academic staff to create online 
course contents and materials in order to create synchronous and asynchronous modes of teaching and learning (Endut et al., 2012). The online platform helps to improve and enhance on-campus teaching where it can deliver any online information to the students as supplement to the traditional teaching and learning approach (Bahner et al., 2012; Endut et al., 2012).

Although the potential use of social media and e-learning was underutilised and underestimated before the COVID-19 pandemic crisis, the current situation has forced educational institutions and educators to adapt swiftly to an all-out online learning. The use of social media and commercial digital learning platforms offer an additional support and solutions to run the education and training continuity in the recent situation. Previous studies have shown that integration of social media into teaching and learning has promoted student learning which led to positive behavioural changes among the health professions students (Paton et al., 2011; Potts, 2011). Besides, positive learners' satisfaction was observed with integration and intervention of social media which directed to more supportive learning communities, improved professional development and enhanced collaboration among colleagues (Cheston et al., 2013).

However, although the technologies have gained interest among health students including dentistry, the educators on the other hand felt unequipped to adapt to the new environment (Spallek et al., 2015). Among the contributing factors were the lack of preparedness among the educators and distraction effect of technologies among students (Endut et al., 2012; Spallek et al., 2015). Besides, excessive use of the technology was found to adversely affect user's health and behaviour (Deogade et al., 2017). With regard to the COVID-19 pandemic, teaching and learning activities are transformed tremendously with the help of technology. Although previous studies had acknowledged the social media as a medium of communication and potential source of information (Bahner et al., 2012; Rung et al., 2014; Usher et al., 2014); the decision why the Malaysian dental students use social media as a source of information for academic purposes among them is still indistinct. Therefore, the present study was conducted to examine the use of social media application among dental students for academic purposes. This study can possibly be valuable to provide useful baseline data for future studies on the potential use of social media application in dental education.

\section{MATERIALS AND METHODS}

\section{Study Design}

This cross-sectional study was conducted from June to August 2018 among undergraduate dental students of Universiti Teknologi MARA (UiTM). All procedures performed in this study were approved by the UiTM Human Ethics Advisory Committee (Ref. No.: 600-IRMI 5/1/6-REC/202/1). Consent was obtained from the respondents before answering the questionnaire via Google Forms. All UiTM undergraduate dental students were invited to participate in this study. An invitation letter was sent via email to students' email group. Emails were sent twice fortnightly to serve as a reminder to answer the questionnaire.

\section{Sample Size Determination}

The calculation of the sample size was determined by Epi Info SoftwareTM version 7.2.3.1 (Centers for Disease Control and Prevention, Atlanta, USA), with expected frequency set as $91.6 \%$ (Alshuaibi et al., 2015), $\alpha=0.05$ and $95 \%$ confidence interval, the minimum sample size required was 118 respondents.

\section{Questionnaire Form}

The questionnaire was divided into two parts. The first part of the questionnaire was adopted from an existing questionnaire in social media study published by Alshuaibi 
et al. (2015). The questionnaire consists of four sections: (1) Socio-demographic characteristics; (2) Smartphone ownership and application; (3) Social media application; and (4) Social media for academic purposes. The questionnaire was maintained in its entirety to preserve the validity of the questionnaire as previously published; with a Likert-scale to rate students' attitude of social media for academic purposes. For content and face validation process, the respondents were asked to indicate degree of relevance of each item based on a Likert scale: $1=$ the item is not relevant to the measured domain; $2=$ the item is somewhat relevant to the measured domain; $3=$ the item is quite relevant to the measured domain; and $4=$ the item is highly relevant to the measured domain. They were also requested to give any comments related to the understanding of the questions. Two dental specialists were appointed for the content validation process. Table 1 shows the result of content validation index of social media use questionnaire by the specialists. Content validation produced an overall validity index of over 0.80 . Universal agreement index (S-CVI/UA) and average index (S-CVI/Ave) was scored 1.00 for all sections $\mathrm{A}, \mathrm{B}$ and $\mathrm{C}$, respectively. Minor modifications were made to improve the structure and to enhance the comprehension of the questionnaire. The questionnaire pretesting was performed within a small sample group of students $(n=5)$ before being distributed among the rest of them. Table 2 shows the result of face validation index of the questionnaire among the students which showed a good acceptability for all sections $(>0.80)$. An open-ended question was also added at the end of the questionnaire for students to provide their opinion regarding the use of social media in dental education. Students were asked the question: "Do you have any comment(s) regarding the use of social media in education?"

\section{Data Analysis}

Data entry and analysis were performed using Statistical Package for Social Sciences (IBM SPSS Statistics for Windows, Version 23.0. Armonk, NY: IBM Corp). Descriptive data analysis was conducted using frequency; percentage for categorical data; mean and standard deviation (SD) for continuous

Table 1 Content validity for social media use questionnaire by two respondents

\begin{tabular}{lccc} 
& \multicolumn{3}{c}{ Section } \\
\cline { 2 - 4 } Item & $\mathbf{A}$ & $\mathbf{B}$ & $\mathbf{C}$ \\
\hline $\mathrm{S}-\mathrm{CVI} /$ Ave & 1.00 & 1.00 & 1.00 \\
$\mathrm{~S}-\mathrm{CVI} / \mathrm{UA}$ & 1.00 & 1.00 & 1.00 \\
Average proportion of items & 1.00 & 1.00 & 1.00 \\
\hline
\end{tabular}

Note: $\mathrm{S}-\mathrm{CVI}=$ scale-level content validity index; $\mathrm{UA}=$ universal agreement calculation method; Ave = averaging calculation method); $\mathrm{S}-\mathrm{CVI} / \mathrm{UA}=$ scale-level content validity index, universal agreement calculation method; $\mathrm{S}-\mathrm{CVI} / \mathrm{Ave}=$ scale-level content validity index, averaging calculation method; Average proportion of items judged relevant across the ten respondents.

Table 2 Response process validity index for social media use by five respondents

\begin{tabular}{lccc} 
& \multicolumn{3}{c}{ Section } \\
\cline { 2 - 4 } Item & A & B & C \\
S-FVI/Ave & 1.00 & 1.00 & 1.00 \\
S-FVI/UA & 1.00 & 1.00 & 1.00 \\
Average proportion of items & 1.00 & 1.00 & 1.00 \\
\hline
\end{tabular}

Note: $\mathrm{S}-\mathrm{VI}$ = scale-level validity index; S-VI/UA = universal agreement calculation method; S-VI/Ave = averaging calculation method; average proportion of items judged clear/comprehensible across 30 respondents. 
type of data accordingly. The data were also tabulated in percentages to indicate the distribution of social media usage for academic purposes among the respondents. Lastly, data analysis for outcome variable was performed using independent $t$-test and one-way ANOVA for significance testing. Assumption of normality for parametric test was also checked. The significant level was set at $p<0.05$. For qualitative part, the written transcript from the open-ended question was analysed by content (O'Cathain \& Thomas, 2004; Nasir et al., 2019). First, the text from the transcript was scanned for repetition of words and phrases. Then, the words and phrases were coded and collated into categories. The final themes based on the categories were formulated and presented. To ensure the reliability of the content, a panel consisting of three different experts took part in the assessment of the data.

\section{RESULTS}

\section{Demographic Characteristics}

A total of 244 undergraduate dental students participated in the study with a total of $67.8 \%$ response rate, and $100 \%$ response rate from third year students. The mean age of respondents was 22.3 years $(S D=1.60)$. The majority of the respondents were females $(85.7 \%)$. Details on the demographic characteristics are shown in Table 3.

\section{Smartphone Ownership and Connection}

Nearly all respondents (99.6\%) had smartphones with $52.5 \%$ of them were iPhone, $47.1 \%$ Android smartphone and $0.5 \%$ of them were Windows-based smartphones. Notably, $91.4 \%$ of them had access to internet data via a third generation (3G) mobile carrier and Wi-Fi connection.

\section{Social Media Application}

Table 4 shows the reasons the respondents use the social media. The majority of the respondents used social media to communicate with friends $(97.1 \%)$, connect with families $(85.7 \%)$ and for business purposes $(5.7 \%)$. Fig. 1 shows the social media membership account and the frequently used social media account by the respondents. The top three social media memberships registered by the respondents were WhatsApp (98\%), Instagram (91.8\%) and Facebook (84.4\%). The most frequent social media accessed by the respondents were WhatsApp (91.0\%) and Instagram $(82.4 \%)$. Most of the respondents indicated that they had logged in into social media multiple times a day (54.1\%). Moreover, $22.1 \%$ stated that there was an increase usage in social media over the past previous years with majority of them stated that the usage of social media remained the same $(63.1 \%)$.

Table 3 Demographic characteristics of respondents according to age, gender and academic year $(n=244)$

\begin{tabular}{lcc}
$\begin{array}{l}\text { Demographic } \\
\text { characteristic }\end{array}$ & $\boldsymbol{n}(\%)$ & Mean (SD) \\
\hline Age (in years) & & $22.33(1.60)$ \\
Gender & \\
$\quad$ Male & $35(14.3)$ & \\
Female & $209(85.7)$ & \\
Academic Year & \\
$\quad$ First year & $34(13.9)$ \\
$\quad$ Second year & $57(23.4)$ \\
$\quad$ Third year & $70(28.7)$ \\
$\quad$ Fourth year & $47(19.3)$ \\
Fifth year & $36(14.8)$ \\
\hline
\end{tabular}

Table 4 Respondent reason for using the social media $(n=244)$

\begin{tabular}{lc} 
Reason cited & $\boldsymbol{n}(\%)$ \\
\hline Connect/communicate with friends & $237(97.1)$ \\
Connect/communicate with family & $209(85.7)$ \\
Network opportunities & $110(45.1)$ \\
Communicate with lecturer & $123(50.4)$ \\
Learn new skill/information & $168(68.9)$ \\
Promote my business & $14(5.7)$ \\
I do not use social media & $1(0.4)$ \\
\hline
\end{tabular}




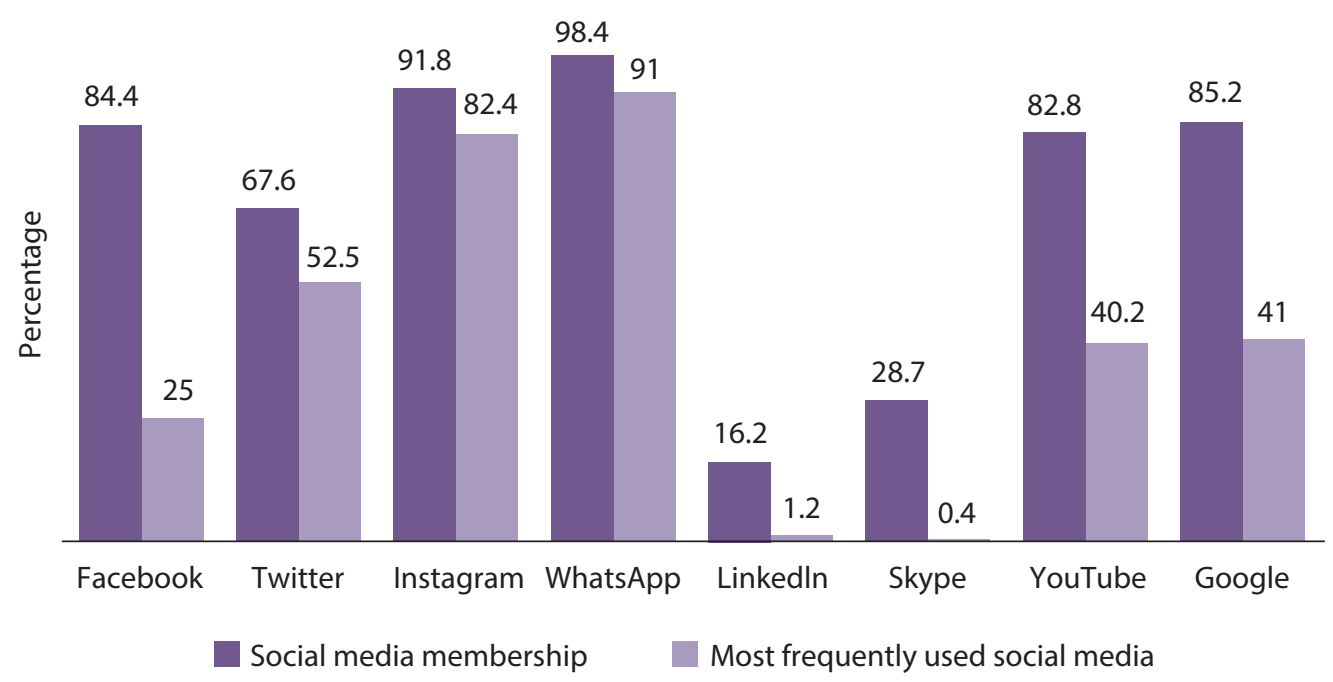

Fig. 1 Social media membership account and the frequently used of social media account by the respondents $(n=244)$.

\section{Social Media for Academic Purpose}

Majority of the respondents $(95.1 \%, n=$ 232) agreed that social media is important to aid in teaching and learning. Fig. 2 shows the social media applications that helped the respondents in their studies. The top five social media applications chosen by the students were YouTube (74.6\%), Google (73.7\%), WhatsApp (55.6\%), Instagram $(33.2 \%)$ and ResearchGate (26.3\%).
Table 5 shows the academic purposes of social media used by the respondents with the majority of the responses were "almost always" and "often". Interestingly, "sometimes" responses were high for organising extracurricular activities (36.9\%) and contacting experts on the topic of study $(31.9 \%)$. The mean score for the academic purposes of social media were 2.87 (0.89), $2.63(0.90)$ and 2.96 (0.81) for exchange information, consultation and queries,

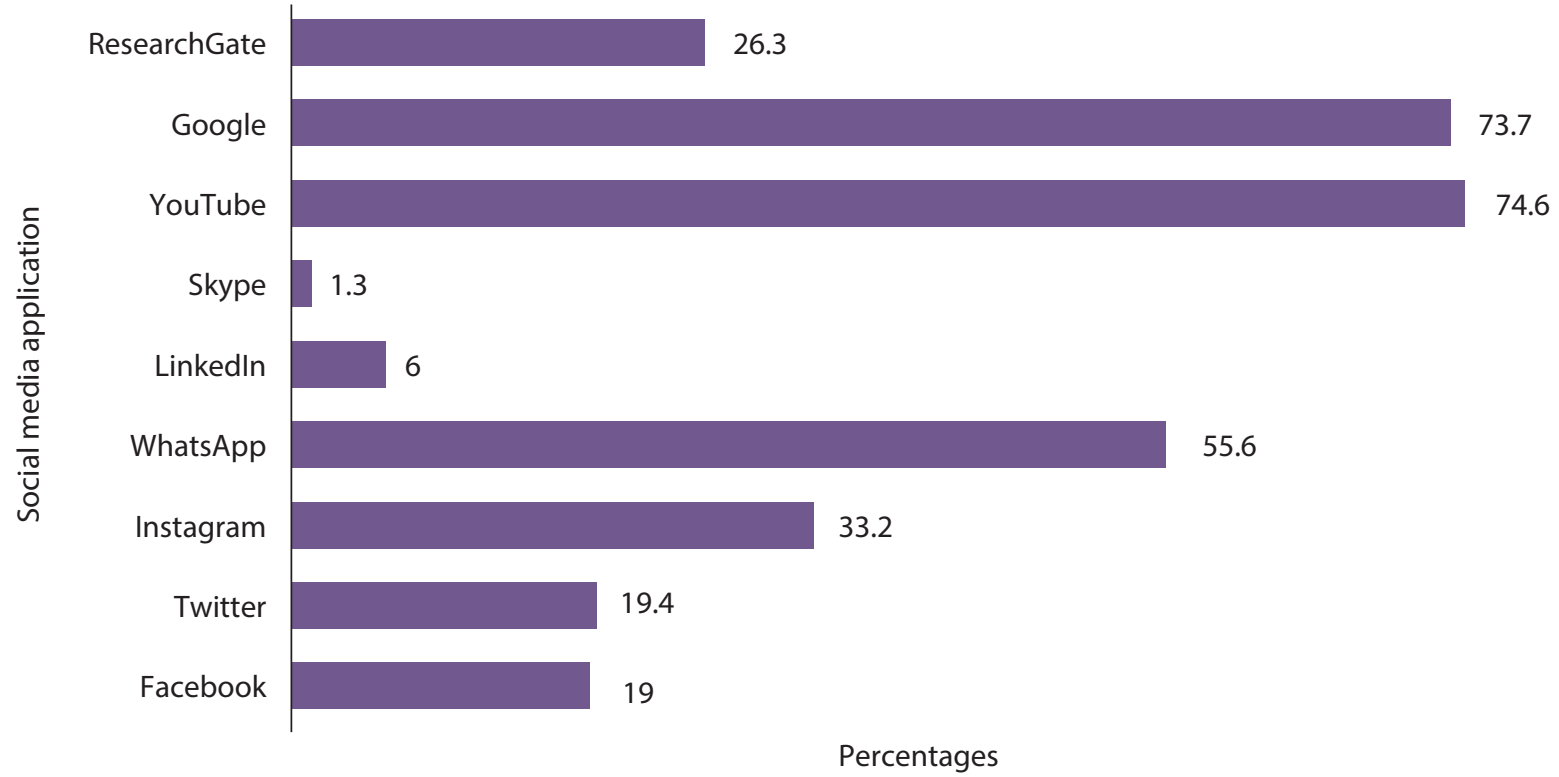

Fig. 2 Application of social media that help the respondents in their studies. 


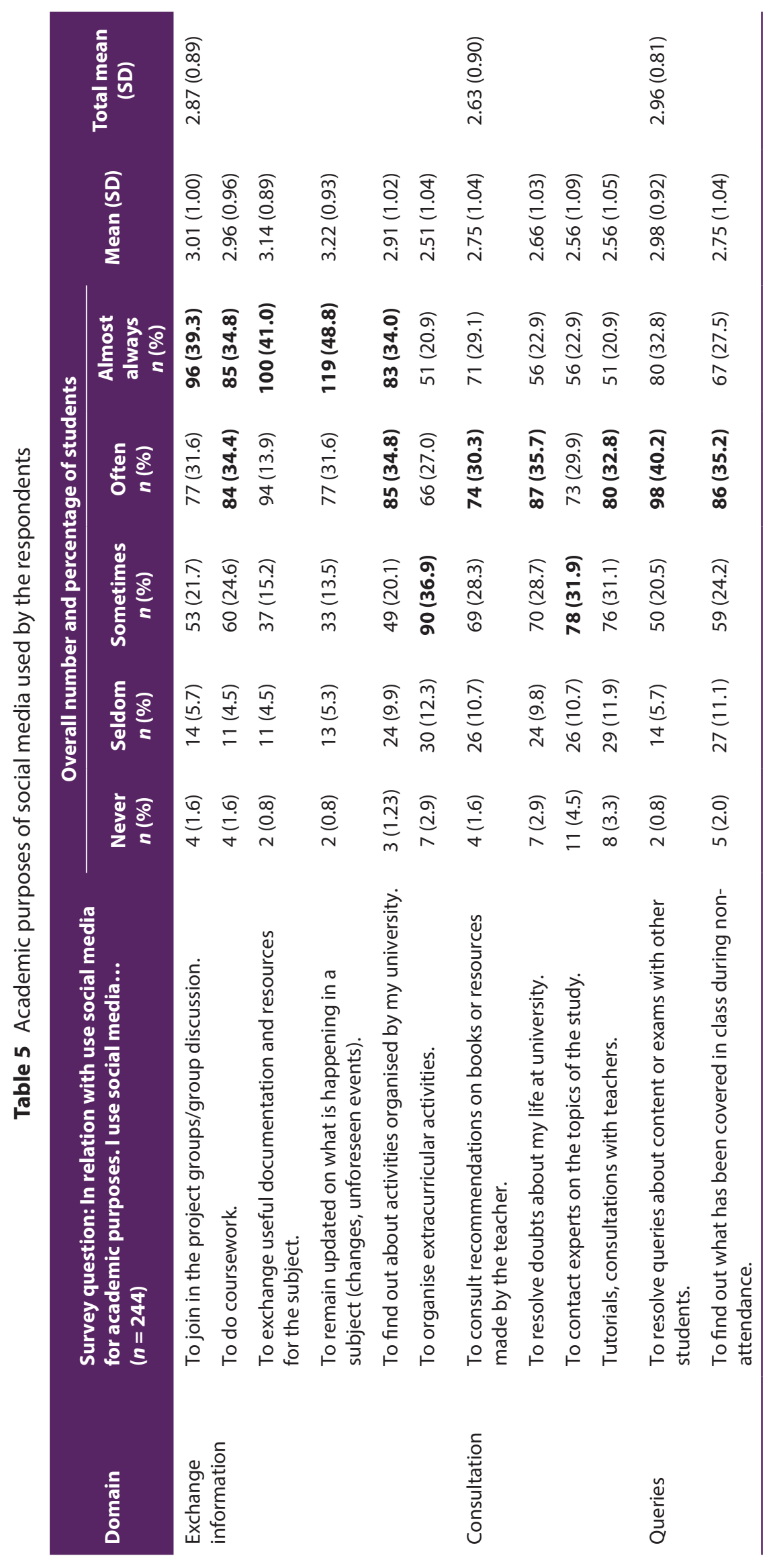


respectively. Table 6 shows the data analysis of gender, year of study and type of internet access by the respondent on the use of social media for any queries, exchange of information and consultation for academic purposes. There were no significant association between gender, year of study and type of internet access with the mean of social media usage for academic purposes.

\section{Open-Ended Question of "Other Comments"}

The open-ended question provided additional comments and responses with regard to social media in education. Responses were received from 56 respondents. After analysis of data (Fig. 3), four major themes were identified. The themes include perception of social media, concern regarding the information, the effect of social media and suggestion for improvement.

Table 6 Data analysis of social media use for queries, exchange of information and consultation for academic purposes

\begin{tabular}{|c|c|c|c|c|c|c|}
\hline \multirow{2}{*}{ Variables } & Queries & \multirow{2}{*}{$p$ value } & Exchange of information & \multirow{2}{*}{$p$ value } & Consultation & \multirow{2}{*}{$p$ value } \\
\hline & Mean (SD) & & Mean (SD) & & Mean (SD) & \\
\hline \multicolumn{7}{|l|}{ Gender } \\
\hline Male & $6.00(1.75)$ & 0.340 & $18.34(5.06)$ & 0.440 & $11.00(3.96)$ & 0.403 \\
\hline Female & $5.69(1.79)$ & & $17.66(4.83)$ & & $10.45(3.53)$ & \\
\hline \multicolumn{7}{|l|}{ Year of study } \\
\hline First year & $5.24(1.82)$ & 0.429 & $16.73(5.60)$ & 0.221 & $9.85(4.33)$ & 0.660 \\
\hline Second year & $5.98(1.90)$ & & $18.89(5.01)$ & & $10.84(3.64)$ & \\
\hline Third year & $5.74(1.76)$ & & $17.47(4.67)$ & & $10.84(3.59)$ & \\
\hline Forth year & $5.83(1.77)$ & & $18.04(4.65)$ & & $10.32(3.51)$ & \\
\hline Fifth year & $5.65(1.58)$ & & $17.08(4.37)$ & & $10.32(2.90)$ & \\
\hline \multicolumn{7}{|l|}{ Internet access } \\
\hline 3G only & $5.75(1.83)$ & 0.921 & $14.50(5.01)$ & 0.135 & $9.50(2.39)$ & 0.714 \\
\hline Wi-Fi & $5.54(2.18)$ & & $17.15(6.39)$ & & $10.54(4.74)$ & \\
\hline $3 G$ and $\mathrm{Wi}-\mathrm{Fi}$ & $5.74(1.76)$ & & $17.91(4.74)$ & & $10.57(3.56)$ & \\
\hline
\end{tabular}

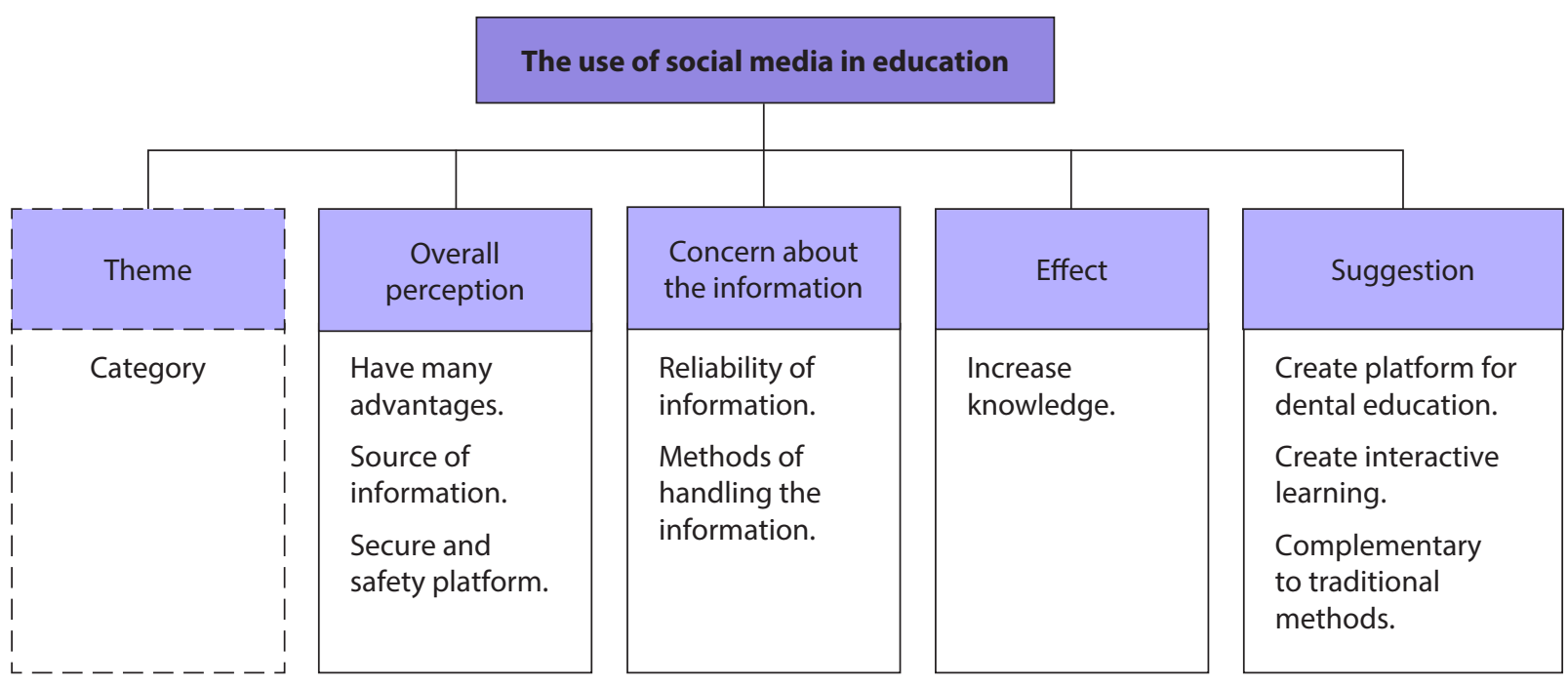

Fig. 3 The respondents comment on the use of social media in education. 


\section{Theme 1: Overall perception}

Most of the respondents claimed that social media is a useful platform to be used and has many advantages in education although a few believed otherwise. They found that social media can be used as a platform to search for information easily and quickly. The information can be accessed and shared whenever needed. They also felt that the platform was safe and secure.

Social media is quite important in education as it always helps me especially in searching new information. (Respondent 114)

Social media is very useful especially in video animation form. The lecturer should always use it in class. (Respondent 100)

\section{Theme 2: Concern about the information}

The respondents were very concerned about the reliability and accuracy of information gathered in the social media. As social media provides immerse range of educational materials, they are worried about validity of information that could be from the inappropriate resources.

Although we can shorten the time to find the information, sometimes the information that we get is incorrect. (Respondent 83)

Students can access information
easily however not all information
are reliable and accurate.
(Respondent 148)

\section{Theme 3: The effect of social media}

Some respondents claimed that social media helped to increase their knowledge in dentistry. They can share and discuss related information with friends, seniors and lecturers which may help to boost their understanding about certain topics.
It is an excellent platform to connect with the other colleagues, seniors and lecturers to exchange new things, sharing opinions and asking questions. (Respondent 64)

\section{Theme 4: Suggestion for improvement}

Respondents believed that teaching and learning via social media can increase student interactivity and can be more engaging. They also felt that the lecturer should contribute their knowledge in social media by creating a specific platform for dental education. Some of them suggested to use video animation or Kahoot! in classes so that the teaching and learning activity become more interactive. Although books and other printed references is the best methods for information search, the respondents believed that social media could complement conventional teaching and learning method where necessary.
Kahoot! is good. Lecturer should use it more often in class. (Respondent 116)
It (social media) should be use more (frequently) by lecturer as it is now popular among students. So, lecturer should take advantage on that. (Respondent 170)

\section{DISCUSSION}

This study was undertaken to identify the use of social media application among dental students and to investigate significant demographic variables with regard to social media use for academic purposes. Nevertheless, our study found that there was no significant association between gender, year of study and type of internet access with the mean of social media usage for academic purposes. WhatsApp, Instagram and Twitter were indicated as the site that they most frequently used to communicate with family and friends, and additionally acts as on the go update platform for students. Our study found that almost half of the respondents agreed that social media keep 
them updated on current state of affairs. Now, most universities and institutions have their own official social media pages such as Facebook and Instagram to inform and convey information as supplement to the official website or email (Stuart et al., 2017).

The current study also revealed that almost half of respondents agreed that they used social media to exchange information rather than consultation or imparting queries. The mean score of social media usage for academic purposes among the respondent was almost similar ranging between the scales of 2 to 3 . It shows that they were sometimes or often used social media for academic purposes. The diversity of social media offers flexible options to the users. Facebook and Instagram were considered as the most popular platforms, but these are most frequently used for personal purposes. It was observed that most of the respondents preferred YouTube and Google for seeking information in their study. YouTube provides more interactive videos and multimedia programmes that is helpful in the learning process as compared to medium that only use static series of slides. This is consistent with a previous study which found the potential use of video sharing platform such as YouTube as the adjunctive educational tool (Knösel et al., 2011). As not all journal articles were assessable through the library subscriptions, ResearchGate was one of the other platforms used by the respondents as it provides an alternative option for researcher to share their publications. It is the largest academic social network which provides additional features that allow researchers to interact and discuss on research topics and helps in increasing publication's visibility (Lantsoght, 2017; Muscanell \& Utz, 2017).

Prior to the COVID-19 pandemic, the integration of social media engagement was not fully utilised by all educators. Nowadays, all learning activities including face-to-face lectures were shifted to virtual online lectures using either the Google Meet (Google Inc., California), Zoom (Zoom
Video Communications, California), WebEx (Cisco Webex, California), or Skype (Skype Technologies, California). Additional functions such as instant chatroom and the ability to record lecture are helpful in providing additional resources to help students in overall learning management. Besides, due to the anonymous condition, interaction using social media allows student to give more responses which can lead to deeper discussion. Similarly, it also allows students to be more focused on the content as they get immediate feedback from the educators (Gikas \& Grant, 2013). Nevertheless, it is important to note that due to the nature of the dental curriculum, virtual online teaching may not be appropriate especially to the clinical year students. Online lectures, clinical case studies and problem-based learning can be adopted as part of teaching and learning, however it cannot entirely substitute in-person clinical experience and human interaction in dental practice. Clinical training, practical and consultation were best done face-to-face along with the patient. Recent study also found that majority of the dental students expressed concern on their clinical training due to the interrupted face-to-face teaching, suspension of practical laboratory sessions and transitioning to online learning during the pandemic crisis (Hung et al., 2021).

There were several limitations in this study. First, this study involved only one dental school in Malaysia, thus it may limit its generalisability to other contexts. For future research, it is suggested that to include all 13 dental schools in Malaysia as part of the study and to introduce more systematic sampling technique in order to have a true representation of the dental school population in Malaysia. Second, the response rate was moderately satisfactory as high response was not achieved, most likely due to the timing of the online questionnaire distribution. The questionnaire distribution was done at the end of semester where most of the clinical students were busy with their clinical requirements while the pre-clinical students were mainly focused on pre-clinical 
examination. Therefore, for future research, it is recommended that the distribution of online questionnaire is done after the class end, in allocated timetable session to increase the participation of respondents.

Despite these limitations, the findings of this study could provide useful preliminary data for educators to design an educational methods and activities that are suitable for social media in order to capture the interest of this new generation of student. With the current situation where COVID-19 created the major intermission of education systems, this study helps to provide a platform for further investigation to explore the use of social media as adjunct method to traditional learning management system. Nevertheless, significant generation gap among students and educators may be hindering the incorporation of this new technologies into the courses (DeBate et al., 2011). Although educators seem to agree that integration with the digital learning style have positive effect in education and can significantly improve the teaching and learning process (Rasiah, 2014), these technologies would be unfamiliar to some faculty members that are digital immigrants, those who were born before the widespread adoption of digital technology. Therefore, for future research it is important to assess the educator's level of understanding and knowledge on the social media, as most of the studies were focusing mainly on student's perception and acceptance in integrating social media into teaching and learning with limited study done on educator's readiness and acceptance (Kenny \& Johnson, 2016; Aboalshamat et al., 2019; Rajeh et al., 2021).

Policy and guidelines informing appropriate conduct in social media among health care professional was already established in countries like America, Australia and United Kingdom (Kind, 2015; General Dental Council, 2016; Australian Health Practitioner Regulation Agency, 2019). With the increasing use of social media among dental student and health care professional; it is recommended to develop social media guidelines at the university level. This will help to provide blueprint and direction on appropriate use of social media as well as to avoid any future implication especially involving issue on confidentiality and privacy of patient.

\section{CONCLUSION}

Most respondents used social media for communication and they acknowledged the importance of social media to aid the teaching and learning activity. Although no significant demographic variables with regard to social media use for academic purposes was found, there is a potential value of integrating social media in teaching and learning activities to enhance students learning experience especially during this epochal event. It offers both opportunities and challenges to our education landscape where dental educator can explore different methods of assimilating social media into the teaching and learning process in order to engage students' interest by addressing students' learning styles and needs.

\section{ACKNOWLEDGEMENTS}

The authors wish to thank Associate Professor Dr. Nik Mohd Mazuan Nik Mohd Rosdy, Dr. Wan Hazirah Wan Ahmad Kamil and Ms. Izyan Hazwani Baharuddin for their assistance with the content validation of the questionnaire. The authors also wish to thank Ms. Nur Saiyidah Hanisah Ali and Ms. Nadia Syahirah Mohd Nazri for assisting in data collection for this study and to all dental students who participated in this study. 


\section{REFERENCES}

Aboalshamat K, Alkiyadi S, Alsaleh S, Reda R, Alkhaldi S, Badeed A, Gabb N (2019). Attitudes toward social media among practicing dentists and dental students in clinical years in Saudi Arabia. Open Dent F, 13(1): 143-149. https://doi.org/10.2174/ 1874210601913010143

Alshuaibi MSI, Alshuaibi ASI, Mohd Shamsudin F (2015). Exploring the patterns of social media use among business students in Malaysia. In: Proceedings of the Asia Pacific Conference on Business and Social Sciences 2015 Kuala Lumpur. pp. 425-434.

Australian Health Practitioner Regulation Agency (2019). Social media: How to meet your obligations under the national law. Retrieved 15 October 2019, from https://www. dentalboard.gov.au/Codes-Guidelines/ Policies-Codes-Guidelines/Social-media -policy.aspx

Bahner DP, Adkins E, Patel N, Donley C, Nagel $\mathrm{R}$, Kman NE (2012). How we use social media to supplement a novel curriculum in medical education. Med Teach, 34(6): 439-444. https://doi.org/10.3109/014215 9X.2012.668245

Cheston CC, Flickinger TE, Chisolm MS (2013). Social media use in medical education: A systematic review. Acad Med, 88(6): 893-901. https://doi.org/10.1097/ ACM.0b013e31828ffc23

de Peralta TL, Farrior OF, Flake NM, Gallagher D, Susin C, Valenza J (2019). The use of social media by dental students for communication and learning: Two viewpoints. F Dent Educ, 83(6): 663-668. https://doi.org/10.21815/JDE.019.072

DeBate RD, Cragun D, Severson HH, Shaw T, Christiansen S, Koerber A et al. (2011). Factors for increasing adoption of e-courses among dental and dental hygiene faculty members. F Dent Educ, 75(5): 589-597.
Deogade SC, Saxena S, Mishra P (2017). Adverse health effects and unhealthy behaviors among dental undergraduates surfing social networking sites. Ind Psychiatry f, 26(2): 207-214. https://doi .org/10.4103/ipj.ipj_67_15

Endut A, Mohd Isa P, Abdul Aziz SR, Hajar MN, Jono H, Abdul Aziz A (2012). e-Learning for Universiti Teknologi MARA Malaysia (UiTM): Campus wide implementation and accomplishments. Procedia Soc Behav Sci, 67: 26-35. https://doi.org/10.1016/j.sbspro.2012.11 .304

General Dental Council (2016). General Dental Council Updates Social Media Guidelines. Retrieved 2 November 2019, from https:// dentistrytoday.com/news/industrynews/ item/1073-general-dental-council-updatessocial-media-guidelines

Gikas J, Grant MM (2013). Mobile computing devices in higher education: Student perspectives on learning with cellphones, smartphones \& social media. Internet High Educ, 19: 18-26. https://doi.org/10.1016/ j.iheduc.2013.06.002

Hung M, Licari FW, Hon ES, Lauren E, Su S, Birmingham WC et al. (2021). In an era of uncertainty: Impact of COVID-19 on dental education. F Dent Educ, 85(2): 148156. https://doi.org/10.1002/jdd.12404

Kenny P, Johnson IG (2016). Social media use, attitudes, behaviours and perceptions of online professionalism amongst dental students. Br Dent f, 221(10): 651-655. https://doi.org/10.1038/sj.bdj.2016.864

Kind T (2015). Professional guidelines for social media use: A starting point. AMA $\mathcal{F}$ Ethics, 17(5): 441-447. https://doi.org/10.1001/ journalofethics.2015.17.5.nlit1-1505

Knösel M, Jung K, Bleckmann A (2011). YouTube, dentistry, and dental education. F Dent Educ, 75(12): 1558-1568. 
Lantsoght E (2017). Using ResearchGate and Academia.edu for research. Retrieved 10 December 2020, from https://www.academictransfer.com/en/blog/ using-researchgate-and-academiaedu-for -research/

Muscanell N, Utz S (2017). Social networking for scientists: An analysis on how and why academics use ResearchGate. Online Inf Rev, 41(5): 744-759. https://doi.org/10.1108/OIR $-07-2016-0185$

Nasir WM, Jaafar A, Abd Wahab R, Harun K, Ali AH (2019). Experiences of left-handed undergraduates in a dental faculty in Malaysia. Arch Orofac Sci, 14(2): 147-156. https://doi.org/10.21315/aos2019.14.2.383

Nguyen VH, Lyden ER, Yoachim SD (2021). Using Instagram as a tool to enhance anatomy learning at two US dental schools. f Dent Educ, 85(9): 1525-1535. https://doi .org/10.1002/jdd.12631

O'Cathain A, Thomas KJ (2004). “Any other comments?" Open questions on questionnaires - a bane or a bonus to research? BMC Med Res Methodol, 4: 25. https://doi.org/10.1186/1471-2288-4-25

Paton C, Bamidis PD, Eysenbach G, Hansen M, Cabrer M (2011). Experience in the use of social media in medical and health education. Contribution of the IMIA Social Media Working Group. Yearb Med Inform, 6: 21-29.

Potts HWW (2011). Student experiences of creating and sharing material in online learning. Med Teach, 33(11): 607-614. https://doi.org/10.3109/0142159X.2011 .610839

Rajeh MT, Sembawa SN, Nassar AA, Al Hebshi SA, Aboalshamat KT, Badri MK (2021). Social media as a learning tool: Dental students' perspectives. F Dent Educ, 85(4): 513-520. https://doi.org/10.1002/jdd.12478
Rasiah RRV (2014). Transformative higher education teaching and learning: Using social media in a team-based learning environment. Procedia Soc Behav Sci, 123: 369-379. https://doi.org/10.1016/j.sbspro .2014 .01 .1435

Robinson $\mathrm{T}$, Cronin $\mathrm{T}$, Ibrahim $\mathrm{H}$, Jinks $\mathrm{M}$, Molitor T, Newman J et al. (2013). Smartphone use and acceptability among clinical medical students: A questionnairebased study. F Med Syst, 37(3): 9936. https://doi.org/10.1007/s10916-013-9936-5

Rung A, Warnke F, Mattheos N (2014). Investigating the use of smartphones for learning purposes by Australian dental students. FMIR Mhealth Uhealth, 2(2): e20. https://doi.org/10.2196/mhealth.3120

Sharka R, San Diego JP, Nasseripour M, Banerjee A (2021). Identifying risk factors affecting the usage of digital and social media: A preliminary qualitative study in the dental profession and dental education. Dent F, 5(3): 923-928. https://doi.org/10 $.3390 /$ dj9050053

Spallek H, Turner SP, Donate-Bartfield E, Chambers D, McAndrew M, Zarkowski $\mathrm{P}$ et al. (2015). Social media in the dental school environment, Part A: Benefits, challenges, and recommendations for use. F Dent Educ, 79(10): 1140-1152.

Stuart E, Stuart D, Thelwall M (2017). An investigation of the online presence of UK universities on Instagram. Online Inf Rev, 41(5): 582-597. https://doi.org/10.1108/ OIR-02-2016-0057

Usher K, Woods C, Casellac E, Glass N, Wilson $\mathrm{R}$, Mayner L et al. (2014). Australian health professions student use of social media. Collegian, 21(2): 95-101. https://doi .org/10.1016/j.colegn.2014.02.004 